\title{
O ESPORTE COMO CONTEÚDO HEGEMÔNICO DAS AULAS DE EDUCAÇÃO FÍSICA EM UMA ESCOLA DE ANÁPOLIS: UM ESTUDO DE CASO
}

DOI: $105902 / 0102830821560$

Data de submissão: 23-03-2016

Data de Aceite: 25-07-2016

Weber Mendes de Paula

Instituto Federal de Educação, Ciência e

Tecnologia de Goiás - IFG maxwebermp@yahoo.com.br

Tadeu João Ribeiro Baptista

Universidade Federal de Goiás tadeujrbaptista@yahoo.com.br

RESUMO: Esta pesquisa pretende analisar o conteúdo esporte como elemento hegemônico nas aulas de educação física de uma escola de Anápolis-Go por meio de um estudo de caso que utilizou como instrumentos a observação, o questionário e a entrevista. Pela pesquisa, pudemos constatar que o ensino é baseado numa postura crítica qualitativamente relevante quanto ao conhecimento científico; porém, na aprendizagem, a produção do conhecimento parece absorver grande influência do senso comum, o que retarda o rompimento com a realidade encontrada no lócus da pesquisa.

PALAVRAS-CHAVE: Esporte; Escola; Educação Física. 


\section{Introdução}

Percebendo o elevado número de programas dedicados exclusivamente ao esporte tanto nos canais de televisão aberta quanto nos canais de televisão por assinatura, diariamente exibidos; somados aos tempos dedicados ao esporte nos telejornais, diariamente; somandose ainda a esses, os programas de rádio dedicados exclusivamente ao esporte e ainda, vinhetas com chamadas esportivas tanto no rádio como na televisão, despertou a nossa atenção para o entendimento desse fenômeno. Com efeito, o esporte também se encontra como conteúdo no ambiente escolar, todavia, em nossa formação inicial e continuada temos o esporte como conteúdo que deve receber o devido tratamento pedagógico no sentido de que venha a mediar a produção do conhecimento da realidade.

Essa discrepância entre o esporte exibido na mídia e sua manifestação no ambiente escolar como elemento de análise para a compreensão da realidade, provocou a busca por uma compreensão mais aprofundada do fenômeno esportivo não somente na base teórica pertinente, mas diretamente no trato com o esporte no ambiente escolar por meio da devida investigação no local em que realizamos o esporte como componente educativo.

A opção de pesquisa pela cidade aludida se deu pelo conhecimento daquela comunidade e, sobretudo, por ser esta pesquisa desprovida de incentivos financeiros. Já a escola que investigamos foi eleita devido à autorização para esta investigação.

Especificamente quanto ao objeto da pesquisa, entendemos que o estudo do esporte enquanto conteúdo instalado no currículo, ainda hoje pode trazer grandes contribuições à educação física escolar porque "[...] o esporte é motivo de debates e questões. Propõe-se que, de certo modo, seja um fenômeno manipulável ao manipularmos as massas por uma ótica salvacionista ao se inferir responsabilidades a ele [...]" (MALINA, 2009, p. 17).

Partindo deste pressuposto, estruturamos como objetivos: conhecer a concepção de educação física e de esporte presente na escola pesquisada; analisar o projeto curricular ali praticado, e identificar a tendência pedagógica materializada nessas aulas de educação física.

Para tanto, este texto se divide em três partes assim constituídas. Na primeira, foi feita uma revisão de literatura na qual procuramos situar o esporte e a educação física. 
$\mathrm{Na}$ segunda, apresentamos a metodologia com os instrumentos utilizados. Na terceira, apresentamos e analisamos os dados da pesquisa. Por esses motivos e outros que serão iluminados no decurso desse artigo, entendemos que esta pesquisa apresenta a devida relevância para a sua realização.

\section{Revendo a literatura a respeito do esporte}

A proposta deste item é apresentar alguns elementos presentes na literatura, os quais têm como foco analisar e discutir a visão do esporte enquanto um conteúdo privilegiado e como componente da educação física escolar.

\subsection{O conteúdo privilegiado: aproximações teóricas}

Como qualquer trabalho organizado previamente, o ensino é antecedido por uma elaboração que pretende se manifestar como produção de uma aula. Nessa direção, os componentes do ensino podem ser destacados quanto ao objetivo do ensino, a metodologia que traduz como será feito o ensino, e o conteúdo que se refere ao que será ensinado.

Já há algum tempo o esporte se encontra na condição de conteúdo privilegiado nas aulas de educação física, provavelmente por sua inserção e influências sociais, e a legitimação de tal idéia é o "[...] discurso de que esporte é cultura, é educação, é integração e inclusão social [...]." (AZEVEDO, 2009, p. 77-78).

É inadequado atribuir ao esporte o atendimento de necessidades humanas, pois, é o trabalho o responsável por viabilizar o vínculo mínimo do indivíduo com a sociedade, no sentido de adquirir bens materiais necessários à sobrevivência humana. Quanto à "[...] saúde, educação, esporte emprego e tudo o mais que atenda às demandas sociais. Só podemos entendê-las enquanto políticas públicas integradas. Isoladamente, nada valem [...]" (MARINHO, 2010, p. 24).

Portanto, é um equívoco, afirmar que o esporte isoladamente consegue sustentar a pretensa idéia da inclusão, pois, efetivamente, o esporte é apenas mais um elemento importante de um conjunto que pode representar uma política pública. Acontradição revelada 
por esses autores, no discurso que posiciona o esporte como o principal componente curricular da educação física na escola (BRACHT, 2009), levando a buscar um entendimento para além do senso comum, porquanto, os determinantes históricos privilegiam o esporte na lógica social.

O fenômeno esportivo faz parte do contexto social e por isso, deve ser considerado como parte de um todo. Entre outros, este argumento pode ser evidenciado no fato de que:

Não foi a vitória brasileira na copa do mundo de 1970 que ratificou a ditadura militar em que estávamos atolados. Mas fez parte do processo de produção de consenso em torno da idéia de que vivíamos um momento glorioso de nossa história. (MARINHO, 2010, p. 22)

Se a sustentação do esporte migra dele próprio para se enraizar em diversos setores da sociedade, passamos a seguinte indagação, como ocorre a articulação do esporte com os diferentes setores sociais?

Para Malina (2009, p. 27):

O esporte, tal como outros fenômenos culturais humanos, estão circunscritos em seu tempo histórico, e não podemos compreendê-lo fora dele. É por isso que atualmente não podemos dissociá-lo da compreensão do modo de produção capitalista, sob o risco de entendermos o esporte em si, como um fenômeno autoexplicável ou fora do seu tempo [...].

O capitalismo se desenvolveu suficientemente para construir universos de ligação entre elementos socioculturais. Neste sentido, os campos econômico e esportivo se articulam em função da reprodução do capital. Isso pode ser evidenciado empiricamente por meio do patrocínio de diferentes empresas, inclusive multinacionais, às equipes que disputam torneios nacionais ou internacionais em diferentes esportes e locais do planeta.

Também pelas propagandas que ocorrem antes, durante, e depois dos eventos esportivos transmitidos pelas mídias, as quais divulgam marcas e ícones que representam grandes empresas relacionando essas marcas com a prática esportiva (BETTI, 1998).

Esses investimentos exorbitantes inserem a imagem dessas marcas na consciência social, que a devolve às empresas por meio de uma busca ampliada de seus produtos, o que se traduz na ampliação dos lucros daquelas empresas porque: 
O esporte de alto rendimento ou espetáculo organiza-se a partir dos princípios econômicos vigentes na economia de mercado - e situa-se no plano da transformação da cultura em mercadoria, é parte do que se chama de indústria do entretenimento [...] (BRACHT, 2005, p. 111).

Por isso, tais universos por sua vez, são constituídos de instituições e agentes que exercem de modo inteligente e concreto, a influência do campo econômico sobre o campo esportivo, conforme nos orienta Bourdieu (1983), haja vista que o segundo está submetido ao primeiro.

Ao analisar a relação entre o esporte e a teoria do campo de Bourdieu, (1983) comenta que existem diferentes pressões as quais passam pelas mídias, a partir dos modelos de vida das classes dominantes. Desse modo, fica evidente o interesse das pessoas que tem o esporte como um meio de vida, o qual é muito disseminado pela mídia.

Por isso, o tão divulgado discurso que elege o esporte como elemento fundamental para a integração/inclusão, em sua essência revela que no esporte, "[...] o processo educativo por ele provocado reproduz inevitavelmente as desigualdades sociais. Por essa razão, pode ser considerada uma forma de controle social" (COLETIVO DE AUTORES, 1992, p 63). Portanto, subserviente à reprodução do capital, antidemocrático e excludente.

Situada a relação estabelecida entre a reprodução do capital e o esporte, avançamos na direção da compreensão do esporte, nesta perspectiva, e sua relação com a educação física escolar.

\subsection{O esporte e a educação física escolar}

Neste item pretendemos expressar o ponto de conexão entre esporte e educação física escolar. Para tanto, partimos do entendimento de que tanto o esporte como a educação física não podem ser analisados isoladamente, especificamente aqui em nosso trabalho no qual a análise do esporte passa pela importância deste como componente educativo a ser tratado na escola, instituição oficial de ensino.

Portanto, para o nosso contexto, é na escola que ocorre esta relação entre esporte e educação física. Mas, o sentido que deve tomar tal relação está fixado pela função social da escola que se manifesta pela necessidade de "promover a apreensão da prática social" 
(COLETIVO DE AUTORES, 1992, p. 63).

Se a escola tem de promover a apreensão da prática social, o trabalho pedagógico desenvolvido deverá manifestar tal apreensão por meio da produção de instrumentos culturais que possibilitem aos estudantes intervirem na prática social a partir de suas realidades cotidianas. Destarte, para que exista um trabalho pedagógico relevante, o conjunto de matérias componentes do trabalho pedagógico a ser realizado deverá alinharse neste objetivo da produção de instrumentos culturais a partir do conhecimento científico tratado em cada matéria.

Neste sentido, a educação física como componente deste conjunto de matérias apresenta a sua contribuição quando,

Busca desenvolver uma reflexão pedagógica sobre o acervo de formas de representação do mundo que o homem tem produzido no decorrer da história, exteriorizadas pela expressão corporal: jogos, danças, lutas, exercícios ginásticos, esporte, malabarismo, contorcionismo, mimica e outros, que podem ser identificados como formas de representação simbólica de realidades vividas pelo homem, historicamente criadas e culturalmente desenvolvidas (COLETIVO DE AUTORES, 1992, p 38).

Há um discernimento clássico na educação física escolar em relação ao esporte: o esporte na escola, "[...] subordina-se aos códigos e significados que lhe imprime a sociedade capitalista e, por isso, não pode ser afastado das condições a ela inerentes [...]" (COLETIVO DE AUTORES, 1992, p 70).

O esporte "[...] através da oferta, na escola, do conhecimento que permite aos alunos criticá-lo dentro de um determinado contexto sócio-econômico-político-cultural" (COLETIVO DE AUTORES, 1992, p 71), possibilita o processo de desenvolvimento e assimilação de uma lógica social estabelecida para garantir os mecanismos de reprodução da sociedade.

[...] importante ressaltar que o esporte foi assimilado pela educação física por acordar com o seu objetivo previsto em lei, que era o de desenvolver a aptidão física e o caráter moral (civismo) do indivíduo, porém "paulatinamente, o esporte se impõe à educação física, ou seja, instrumentaliza a educação física para o atingimento de objetivos que são definidos e próprios do sistema esportivo" (COSTA, 2015, p. 75).

Mas, como podemos conceber o esporte na escola enquanto função social? O esporte na escola é o estabelecimento de uma aproximação máxima do modelo de esporte de rendimento no ambiente escolar. Assim, dada à profundidade de inserção deste modelo de 
esporte na consciência social, no âmbito escolar torna-se de fácil apropriação ainda que pedagogicamente seja de caráter ideológico.

Nessa perspectiva, podemos afirmar que:

Os esportes, aqui e alhures, são meios de propagação dos juízos de valor dominantes que, numa sociedade capitalista, são os juízos de valor da classe dominante. Não há, portanto, um esporte de esquerda e um esporte de direita, mas apenas o esporte servindo a uma ou outra classe social como meio de propaganda de suas idéias. (FREITAS, 2009, p. 55)

Evidentemente, os juízos de valor dominantes avançam sobre o ambiente da escola, contudo, a escola tem como função social "[...] formar o cidadão crítico e consciente da realidade social em que vive, para nela intervir na direção dos seus interesses de classe." (COLETIVO DE AUTORES, 1992, p. 36). Esta condição torna incoerente o modelo de esporte de rendimento com a realidade da escola pública e laica.

Por outro lado, a realidade da escola apresenta um quadro em que, "[...] qualquer que seja a função ou papel do esporte para a formação humana, na escola esse papel é potencializado, em especial pela democratização da prática e por ser a escola um espaço formativo (...)" (AGRÍCOLA, 2007, p. 12).

Considerando que o modelo de alto rendimento é o modelo que se multiplica no senso comum permeando assim a consciência social, entendemos que atualmente intensificam os

[...] processos que transformam seres humanos em mercadoria, como é o caso dos atletas, investimento este que inicia na escola, nas "escolinhas", nas seleções realizadas pelos "olheiros", culminando nas transações internacionais da mercadoria atleta. Intensificam-se os processos de espetacularização e a esportivização em todos os âmbitos da vida e principalmente na escola, com tudo que lhes é peculiar - competitividade, produtividade, individualismo, tecnicização (TAFFAREL, 2009, p. 191).

O conteúdo esportivo na escola, por articulação dos agentes capitalistas atuantes em distintos setores sociais, interessados na difusão do modelo do alto rendimento, vem estabelecendo uma permuta com a disciplina educação física, quando se permeia a consciência social por força do senso comum. Ainda que, a educação física seja, 
Uma disciplina que trata, pedagogicamente, na escola, do conhecimento de uma área denominada cultura corporal, [...] constituída de atividades como o jogo, esporte, ginástica, dança e outras que visam apreender a expressão corporal como linguagem [...] (COLETIVO DE AUTORES, 1992, p. 62).

Assim, o esporte parece absorver a educação física alojando-se como o seu ápice, tornando-se a principal referência da cultura corporal, e simultaneamente suplantando os demais conteúdos, quando demonstra "[...] claramente que a finalidade a ele atribuída é só a vitória na competição, colocando-o como fim em si mesmo" (COLETIVO DE AUTORES, 1992, p 71).

Porém, para a compreensão da realidade do lócus da pesquisa acreditamos que o ensino e o aprendizado do esporte na construção concreta da aula de educação física nos possibilitarão visões mais É

[...] importante ressaltar que o esporte foi assimilado pela educação física por acordar com o seu objamplas que norteiam esta realidade.

\section{Metodologia da pesquisa}

Este é um estudo descritivo de caráter transversal realizado em uma escola estadual do município de Anápolis - Go, sendo os instrumentos usados foram:

1. Um questionário com 9 perguntas a 44 alunos do primeiro e segundo ano matutino do ensino médio;

2. A observação de duas aulas da professora da disciplina;

3. Análise do projeto-político pedagógico da escola por dar maior capacidade de compreensão dos diferentes objetivos da educação física nesta escola.

No que se refere ao projeto-político e pedagógico foi informado que o mesmo estava sendo construído, enquanto o do ano anterior se encontrava defasado, motivos que impediram a análise. Este fato lamentavelmente inviabilizou a aplicação deste valioso procedimento em nossa pesquisa.

Este quadro não afasta perspectivas que permitem trabalhar no campo da hipótese e assim aproximarmos daquilo que motivou o não acesso ao projeto-político e pedagógico 
inerente àquela unidade de ensino, como veremos posteriormente.

O questionário aplicado a 44 alunos de $1^{\circ}$ e $2^{\circ}$ ano do ensino médio, período matutino, com idade média de 15 anos, sendo $37,40 \%$ do sexo masculino e $62,60 \%$ do sexo feminino. Procurou-se apreender a metodologia de ensino, os objetivos, a abrangência desses, e a prioridade do conteúdo esportivo nas aulas de educação física. Optamos pelo questionário constituído de perguntas abertas porque entendemos que este valoriza sobremaneira a participação daquele que o responde, quando lhe proporciona ampla liberdade nas respostas.

Já a observação das aulas de educação física pretendeu conhecer a tendência pedagógica praticada, o tipo de formação do professor regente e a disponibilidade de materiais.

\section{Sistematização, apresentação e análise dos dados.}

Nessa direção, encaminhamos primeiramente as respostas que se colocaram de modo objetivo, e estas ao serem analisadas, demonstraram o entendimento e a linguagem dominante no grupo pesquisado.

Procuramos então estabelecer as categorias presentes no questionário, a fim de apreender a essência descrita pelo questionado no que tange a relação educação física/ esporte, objeto central de nossa pesquisa.

\subsection{Das respostas dos alunos}

$\mathrm{Na}$ tabela 1 apresentamos os resultados das concepções de educação física apresentadas pelos alunos. Dos 44 alunos, 34,12\% responderam que a educação física é sinônimo de esporte, $18,18 \%$ disseram que a educação física é explicada pelos conteúdos do campo. Outros percentuais menores apontaram que educação física é exercício (11,36\%), jogo (6,81\%), saúde, diversão e educação (4,54\% cada), mas, 7 alunos $(15,9 \%)$ não responderam a esta pergunta, o que demonstra, provavelmente dificuldade dos próprios professores definirem o que é educação física. 
Tabela 1: Concepção de Educação física apresentada pelos alunos.

\begin{tabular}{lcc}
\hline \multicolumn{1}{c}{ Concepção de Educação Física } & $\mathrm{f}$ & $\%$ \\
\hline Esporte & 15 & 34,12 \\
Referiram-se aos conteúdos da área & 8 & 18,18 \\
Exercícios & 5 & 11,36 \\
Jogo & 3 & 6,81 \\
Saúde & 2 & 4,54 \\
Diversão & 2 & 4,54 \\
Educação & 2 & 4,54 \\
Não responderam & 7 & 15,9 \\
\hline
\end{tabular}

Esse dado pode expor o esporte como à própria educação física, o que caracteriza de fato este conteúdo como prioritário entre os pesquisados, confirmando as orientações de Bracht (2009), quando afirma que o esporte predomina como conteúdo da educação física escolar.

Na tabela 2, os alunos responderam à pergunta: $\mathrm{O}$ esporte da escola deve ser diferente do esporte do clube? Do total de alunos, $\quad 29,54 \%$ disseram que não e o motivo quando foi perguntado é porque na visão destes adolescentes, todos acreditam que a escola deve instrumentalizar para atender o clube.

Tabela 2: Diferenciação do Esporte da Escola e do Clube.

\begin{tabular}{|c|c|c|}
\hline Resposta & F & $\%$ \\
\hline Não & 13 & 29,54 \\
\hline $\mathrm{Sim}$ & 31 & 70,45 \\
\hline
\end{tabular}

Para os 31 alunos $(70,45 \%)$ que responderam que a escola deve ter uma aula de esporte diferente, as respostas foram analisadas e estão apresentadas na tabela 3. Os alunos demonstram aqui uma compreensão crítica, pois, eles apresentam ter certa clareza de que o esporte da escola deve compreender. Por outro lado, alguns alunos limitam isso pela lógica de um nível insuficiente de aprendizagem de cada modalidade. Todavia, pode-se considerar a capacidade dos alunos identificarem a necessidade de se 
estabelecer um padrão de educação física da escola, como diria Caparroz (2005).

Tabela 3: Motivos pelos quais os alunos acreditam que o esporte da escola deve ser diferente.

\begin{tabular}{lcc}
\hline \multicolumn{1}{c}{ Motivo } & F & $\%$ \\
\hline Devemos aprender, não só praticarmos, e não só o esporte. & 21 & 67,74 \\
Porque na escola aprendemos só o básico & 10 & 32,26 \\
Total & 31 & 100,0 \\
\hline
\end{tabular}

$\mathrm{Na}$ tabela 3, dos 31 que responderam sobre a necessidade da diferença $67,74 \%$ responderam que a educação física possui outros conteúdos, e seu objetivo na escola é ensiná-los e não somente praticá-los, e por este motivo se difere e muito do esporte no clube. Esse posicionamento aproxima-se da ideia de que "[...] o esporte não precisa ser tematizado na sua forma tradicional, com vistas ao rendimento, mas com vistas ao desenvolvimento do aluno (...)" (KUNZ, 1994, p 28).

Em relação à pergunta, o que faz com que o esporte seja tão conhecido e praticado, as respostas se encontram na tabela 4. Aqui, a ideia do esporte como cultura é bastante interessante e demonstra uma compreensão ampliada do esporte com um fenômeno social. A competição aparece como um segundo elemento considerando o fato de que esta é, inequivocamente, a dimensão mais significativa do esporte. O aspecto do esporte como saúde se dá, provavelmente, pela disseminação da ideia de que as alterações provocadas pelo treinamento levam a níveis aumentados de saúde. por último temos a noção de diversão e, finalmente, chama a atenção o fato de um percentual menor de alunos não ter respondido a esta questão.

Tabela 4. Motivos que fazem o esporte ser tão conhecido.

\begin{tabular}{lcc}
\hline \multicolumn{1}{c}{ Respostas } & F & $\%$ \\
\hline Cultura & 39 & 25 \\
Competição & 10 & 22,72 \\
Saúde & 9 & 20,45 \\
Diversão & 8 & 18,18 \\
Não responderam & 6 & 13,63 \\
\hline
\end{tabular}


Nas respostas, o conceito de cultura emerge do senso comum, e, portanto, pode ser entendido enquanto costumes construídos e praticados ao longo do tempo por determinado grupo e que não se confunde com trabalho. Portanto, interpretamos ainda um imenso equívoco neste posicionamento, pois, mesmo sendo o esporte uma forma de representação cultural, não podemos "[...] dissociá-lo da compreensão do modo de produção capitalista, sob o risco de entendermos o esporte em si, como um fenômeno auto-explicável ou fora do seu tempo" (MALINA, 2009, p. 27).

Ao eleger o esporte como cultura, parece que o público o fez extraindo o elemento cultural do contexto das relações globais, porquanto, "[...] o entendimento do esporte enquanto fenômeno social não pode considerá-lo como parte de uma realidade, [...] não podemos colocá-lo entre 'parênteses' esquecendo as condições e produção de sua existência" (MARINHO, 2010, p 22).

Assim, podemos afirmar que o conceito de esporte como cultura, advém do senso comum e não se sustenta, por ser compreendido de modo fragmentado e divorciado das condições que o produz.

\subsection{Observação das aulas e diálogo com a professora titular:}

A professora observada possui graduação em educação física e especialização em educação física escolar, realizadas, ambas, em universidades públicas. Ela é concursada pela rede estadual de ensino e, além dela, a escola conta com mais dois professores de educação física no mesmo turno.

As aulas observadas tiveram como tema o esporte da escola, e nestas foi possível interpretar os elementos a seguir.

- A participação/interesse dos alunos foi massiva, a professora demonstrou domínio da turma e uma relação muito amistosa com os alunos, sempre esclarecendo pontos problemáticos e destacando questões inerentes ao conhecimento científico ali em produção, vinculando-o com a realidade vivida pelos educandos.

- As aulas foram conduzidas por meio de uma metodologia que se enquadra em estratégias de ensino denominadas transcendências de limites (KUNZ, 1994), em que os estudantes vivenciaram determinados momentos do atletismo em três fases distintas e 
consecutivas: a da experimentação, a do aprendizado e a de inovação do que foi ensinado/ aprendido, aproximando-se da perspectiva crítico-emancipatória.

- Nesse sentido, baseado no ensinamento de que o papel da educação crítica é dar condição "[...] concreta ao esforço para garantir aos trabalhadores um ensino da melhor qualidade possível nas condições históricas atuais." (SAVIANI, 1991, p. 42), pudemos interpretar claramente uma abordagem crítica nas aulas, preocupada com a produção do conhecimento científico. A criticidade da professora foi confirmada pelo diálogo ampliado pela amplitude de conhecimento do campo da educação física.

\subsection{A materialidade do conteúdo hegemônico nas aulas de educação física escolar}

A aprendizagem ocorre quando, componentes do conteúdo aprimoram a qualidade de pensamento dos estudantes segundo demonstra o Coletivo de Autores (1992). Desse modo, buscamos identificar no ensino e na aprendizagem, os elementos pedagógicos fundamentais à produção do conhecimento científico elaborado acerca do conteúdo esporte.

Nesse horizonte, as aulas manifestaram estratégias que estabeleciam um ensino do esporte "[...] compreendido na sua dimensão polissêmica [...] abrangendo também, colocarse na situação dos outros participantes, visualizar componentes sociais e ações culturais no campo esportivo" (BRODTMANN; TREBELS, 1979 apud KUNZ, 1994, p. 28).

Constatamos neste desenvolvimento estratégico, conforme é demonstrado por Kunz (1994, p. 117), “[...] a forma criativa ou inventiva de diferentes práticas esportivas a partir das duas formas anteriores da representação do saber", a forma experimental e a forma aprendida, pois, no transcurso da metodologia, a explicitação e exemplificação dos elementos didático-pedagógicos eram vinculadas a realidade dos alunos buscando explicar a realidade complexa.

Reconhecemos essa postura enquanto posicionamento inserido numa abordagem crítica uma vez que na escola, os conteúdos devem possibilitar ao aluno "[...] entender a realidade social interpretando-a e explicando-a [...]" (COLETIVO DE AUTORES, 1992, p. 63).

Por outro lado, numa perspectiva mais ampliada, percebemos a conexão entre eixotemático, conteúdo e metodologia, constituindo um bloco unitário que de fato materializou 
o ensino do esporte desmistificando-o de um modo que "[...] permitiu aos alunos criticálo dentro de um determinado contexto sócio-econômico-político-cultural" (COLETIVO DE AUTORES, 1992, p. 71). Desse modo, consideramos que a maneira como o esporte é tratado na escola pesquisada é contraditória, considerando a coexistência de perspectivas críticas e do senso comum no mesmo espaço.

\section{Considerações FInais}

Para a construção de um posicionamento coerente com a pesquisa resgataremos os nossos principais questionamentos que motivaram este trabalho: conhecer a concepção de educação física presente na escola pesquisada. Apesar de não termos apresentado as diferentes vertentes da Educação Física, como, a desenvolvimentista, a construtivista, entre outras, compreendemos que esta pesquisa tenta evidenciar que existe a possibilidade de construir metodologias críticas de educação física. Apesar de saber das diferentes concepções paradigmáticas e de termos, como opção um olhar a parti do materialismo dialético, ainda assim, identificamos a preferência pela perspectiva crítico-emancipatória no contexto pesquisado.

Reportando aos dados da pesquisa, constatamos que $34,12 \%$ dos entrevistados afirmaram que educação física é o esporte, ainda que a professora trabalhe com uma perspectiva ampliada e, em nossa compreensão, crítica. Outro ponto importante foi identificarmos que para $70,45 \%$ dos alunos o esporte da escola deve ser diferente do ensinado no clube.

Desses, $67,74 \%$ responderam que o motivo para essa diferença é a necessidade de aprender outros conteúdos e ampliar/aprofundar os conhecimentos sobre o esporte, e não somente praticá-lo na condição do fazer pelo fazer.

Quando incluída a comparação entre o esporte da escola e do clube, a contradição se coloca entre o que os estudantes expressam no primeiro e no segundo momento, ou seja, um paradoxo a partir de um mesmo grupo de indivíduos, representado pela criticidade de alguns e pelo senso comum dos outros. Depreendemos dos dados, que a categoria contradição surge como elemento chave para a compreensão do papel do esporte na 
escola.

A segunda questão que nos propusemos, foi analisar o projeto curricular praticado, e identificar a tendência pedagógica materializada nessas aulas de educação física, o qual não foi feito por não termos acesso ao projeto curricular. Apesar de não ter sido concedida uma entrevista com a equipe gestora, podemos trabalhar com algumas hipóteses acerca do projeto curricular.

1. O projeto curricular é infiel no que se refere às matrizes teóricas e se coloca como uma mistura de métodos que agradam a todos. Nesse caso, a pesquisa revelaria essa infidelidade e, portanto, exporia tal fragilidade incompatível com um processo educativo emancipador.

2. O projeto curricular, em suas funções, inexiste formalmente, por isso, acredita-se que este fato pode facilitar o controle do processo por parte das chefias ligadas aos agentes políticos que dominam o quadro vigente.

3. No caso da tendência pedagógica predominante, apresenta indícios de uma abordagem crítica. Analisaremos a questão, incluindo o questionamento: Conhecer por que o esporte enquanto conteúdo componente do currículo da educação física escolar se coloca como hegemônico nas aulas? Uma abordagem crítica naturalmente desmistificaria o esporte hegemônico e, portanto não Ihe daria primazia em relação a outros conteúdos.

4. Porém, $34,12 \%$ dos entrevistados afirmaram que educação física é esporte, e novamente a incoerência entre os dados ergue uma contradição chave, porque "[...] a totalidade sem contradição é vazia, inerte" (HEGEL apud KUENZER, 1998, p. 65).

As contradições encontradas em nossa pesquisa no polo da aprendizagem no processo educativo encontram-se crivadas de uma poderosa influência oriunda do senso comum especialmente baseada nas mídias, o que podemos chamar de educação informal baseada na "[...] interpretação, interiorização e expressão do mundo que preexiste ao sujeito" (CURY, 1989, p. 104).

Porém, a "[...] possibilidade de ultrapassar os discursos pedagógicos que ocultam ou escamoteiam o real está na descoberta do caráter contraditório das mesmas relações que estes discursos tentam encobrir" (IDEM, p. 16).

Por isso, o tão divulgado discurso que estabelece o esporte como hegemônico entre os conteúdos da educação física, que se move no senso comum por meio da educação 
informal, pretende atuar enquanto,

Forma de consciência social (ideologia), que veicula os interesses, valores, ética, e moral da classe dominante como universais visando manter a posição privilegiada que essa classe ocupa na sociedade, e a qualidade de vida construída e conquistada a partir desse privilégio (COLETIVO DE AUTORES, 1992, p. 24).

Neste sentido, a forma central de expressão da contradição entre as classes sociais se ocultam em categorias fundamentadas no princípio da "não-contradição", (CURY, 1989) e assim, o esporte enquanto hegemônico surge como elemento integrante de algumas das categorias que pretenda produzir um consenso social divorciado da realidade.

Contudo, destacamos um trabalho docente que se aproxima de uma abordagem crítica (SAVIANI, 1992, p. 42), compreendemos então, que no terreno da aprendizagem, o trabalho desenvolvido pela professora não se articula com a captação oriunda da educação informal (CURY, 1989). Pelo contrário, pretende romper com tal concepção hegemônica de esporte e sociedade, apesar de os dados não apontarem para o uso de outros conteúdos, apesar de conteúdos não esportivos serem anunciados pela professora pesquisada.

Todavia, o rompimento com o estabelecido representa:

Uma disputa no âmbito do movimento histórico pela transformação estrutural da sociedade. E esse movimento que orienta a ação revolucionária dos homens comporta alguns momentos como desestabilizar, estruturar, convencer e consolidar (CHAUÍ apud COLETIVO DE AUTORES, 1992, p. 43).

Nessa visão, entendemos que ainda que esteja sendo construído um trabalho engajado numa perspectiva crítica da educação, o processo de rompimento com o estabelecido necessita de tempo para a sua superação e não ocorre isoladamente do todo estruturado que o cerca, influenciando e sendo influenciado a todo o momento.

Entendemos enfim, que o trabalho docente produzido no lócus da pesquisa encontra-se em um dos momentos do processo que pode produzir o rompimento com o estabelecido, aqui traduzido como a hegemonia do esporte enquanto conteúdo da educação física escolar. 


\section{Referências}

AGRíCOLA, Nestor Pérsio Alvim. Esporte, esporte escolar e competição: sentidos, ações e contradições. Goiânia: ed. da UCG, 2007.

AZEVEDO, Ângela Celeste Barreto de. Bases Teóricas de Prescrição para Formulação de projetos Pedagógicos. (Tese de Doutorado). UGF, Rio de Janeiro, 2004.

BETTI, Mauro. A Janela de Vidro. Campinas: Papirus, 1998.

BOURDIEU, P. Questões de sociologia. Rio de Janeiro: Editora Marco Zero, 1983.

BRACHT, Valter. Sociologia Critica do esporte: uma introdução. Ed. Unijuí, juú, 2005.

CAPARROZ, F. E. Entre a Educação Física na escola e a Educação Física da escola. 2. ed. Campinas: Autores Associados, 2005.

CARLAN, P.; KUNZ, E.; FENTERSEIRFER, P. E. Esporte como conteúdo da Educação Física escolar: estudo de caso de uma prática pedagógica "inovadora". Movimento. Porto Alegre, v. 18, n. 04, p. 55-75, out/ dez de 2012.

COLETIVO DEAUTORES. Metodologia do ensino de educação física. São Paulo: Cortez 1992.

COSTA, Jonatas M. da. Esporte Escolar no Brasil: contradições e possibilidades. Revista Kinesis. v. 33, n. 1, p. 71-86, jan.-jun. de 2015.

CURY, Carlos Roberto Jamil. Educação e contradição, elementos metodológicos para uma teoria crítica do fenômeno educativo. São Paulo: Cortez, 1989.

FREITAS, L. C. Critica da organização do trabalho pedagógico. Campinas: Papirus, 2000. 
KUENZER, A. educação e trabalho no Brasil: o estado da questão. In FRIGOTTO, Galdêncio (Org.). Educação e crise do trabalho: perspectivas de final de século. Petrópolis, Rio de Janeiro: Vozes, 1998.

KUNZ, Elenor. Transformação didático-pedagógica do esporte. ljuí: Unijuí, 1994.

MALINA, André. Esporte: fator de integração e inclusão social? Campo Grande, MS: Ed. UFMS, 2009.

MARINHO, Vitor. O esporte pode tudo. São Paulo: Cortez, 2010.

SAVIANI, Demerval. Escola e democracia. Campinas: Autores associados, 1991.

SOUZA, S. Avaliação da aprendizagem na escola de primeiro grau: legislação, teoria e prática. Dissertação (Mestrado em Educação), PUC/SP, São Paulo, 1986. 


\section{SPORT AS HEGEMONIC CONTENT OF PHYSICAL EDUCATION CLASSES IN A ANÁPOLIS SCHOOL: A CASE STUDY}

ABSTRACT: This research aims to analyze the sport contents as a hegemonic element in physical education classes in an Anápolis school through a case study that used as instruments observation, questionnaire and interview. For the research, we found that the teaching is based on a qualitatively relevant critical attitude towards the scientific knowledge; But, the learning, knowledge production seems to absorb large influence of common sense, which slows the break with the reality found in the locus of research.

KEYWORDS: Sport; School; Physical Education.

\section{EL DEPORTE COMO CONTENIDO HEGEMÓNICO DE LAS CLASES DE EDUCACIÓN FÍSICA EN UN ESCUELA DE ANÁPOLIS: UN ESTUDIO DE CASO}

RESUMEN: Esta investigación busca analizar el contenido del deporte como elemento hegemónico en las clases de educación física de la escuela de Annapolis a través de un estudio de caso que utiliza como instrumentos la observación, cuestionarios y entrevistas. Para la investigación, se encontró que la enseñanza se basa en una actitud crítica cualitativamente relevante hacia el conocimiento científico; Pero el aprendizaje, la producción de conocimiento parece absorber gran influencia del sentido común, lo que ralentiza la ruptura con la realidad que se encuentra en el lugar de la investigación.

PALABRAS CLAVE: Deporte; Escuela; educación física. 